\title{
Dynamics of $P$. vivax clones in a cohort of children with or without primaquine treatment at baseline
}

\author{
Rahel Wampfler ${ }^{1,2^{*}}$, Leanne Robinson ${ }^{3,4}$, Natalie Hofmann ${ }^{1,2}$, Andreea Waltmann ${ }^{3,5}$, Inoni Betuela ${ }^{4}$, \\ Mariabeth Silkey ${ }^{1,2}$, Peter Siba ${ }^{4}$, Tom Smith ${ }^{1,2}$, Ivo Mueller ${ }^{3,6}$, Ingrid Felger ${ }^{1,2}$ \\ From Challanges in malaria research: Core science and innovation \\ Oxford, UK. 22-24 September 2014
}

P. vivax was detected by PCR in $45 \%$ of children aged 5 10 years from our study area in Papua New Guinea (PNG). 504 children were randomized into 2 arms according to Primaquine (PQ) treatment or not at baseline and actively and passively followed for 9 months. We genotyped all $P$. vivax infections, the majority of these being multi-clone infections. All blood samples positive for $P$. vivax by qPCR were tested for gametocyte carriage by targeting pvs 25 transcripts. Primaquine reduced the risk of $P$. vivax infections by $80 \%$. The multiplicity of infection and the density of asexual $P$. vivax stages were not significantly different in both treatment arms. The number of new clones (force of blood-stage infection) was $2.38 \pm 0.17$ per person per year-at-risk in the PQ-arm compared to $8.04 \pm 0.41$ in the Placebo arm $(P<0.05)$. The duration of infections did not differ between the treatment arms, with 73 days [95\% CI: 33849] and 68 days [95\% CI: 40-247] in the PQ or Placebo arm, respectively. Detectability of $P$. vivax clones was low with $0.26 \pm 0.06$ and $0.24 \pm 0.04$ in the PQ and Placebo arms. PQ-treated children had a $75 \%$ lower risk of carrying gametocytes compared to Placebo recipients. $P$. vivax positive children in both arms were equally likely to show gametocyte positivity. We conclude that $P$. vivax relapses contribute significantly to the high burden of P. vivax infection and transmission in PNG. All other infection dynamics parameters were consistent between treatment arms and apparent relapses behave like new infections.

\section{Authors' details}

${ }^{1}$ Swiss Tropical and Public Health Institute, Basel, Switzerland. ${ }^{2}$ University of Basel, Basel, Switzerland. ${ }^{3}$ Walter and Eliza Hall Institute, Parkville, Australia. ${ }^{4}$ PNG Institute of Medical Research, Madang \& Maprik, Papua New Guinea.

${ }^{1}$ Swiss Tropical and Public Health Institute, Basel, Switzerland

Full list of author information is available at the end of the article
${ }^{5}$ Department of Medical Biology, University of Melbourne, Victoria, Australia. ${ }^{6}$ Centre de Recerca en Salut Internacional de Barcelona (CRESIB), Barcelona, Spain.

Published: 22 September 2014

doi:10.1186/1475-2875-13-S1-O24

Cite this article as: Wampfler et al:: Dynamics of $P$. vivax clones in a cohort of children with or without primaquine treatment at baseline. Malaria Journal 2014 13(Suppl 1):O24.

Submit your next manuscript to BioMed Central and take full advantage of:

- Convenient online submission

- Thorough peer review

- No space constraints or color figure charges

- Immediate publication on acceptance

- Inclusion in PubMed, CAS, Scopus and Google Scholar

- Research which is freely available for redistribution 